Research Article

\title{
Effects of Industrial and Agricultural Wastes on Mud Blocks Using Geopolymer
}

\author{
N. P. Vignesh (D, K. Mahendran, and N. Arunachelam \\ Centre for Rural Technology, The Gandhigram Rural Institute (DU), Dindigul, India \\ Correspondence should be addressed to N. P. Vignesh; np.vignesh@gmail.com
}

Received 8 August 2019; Accepted 4 November 2019; Published 11 January 2020

Guest Editor: Majid Ali

Copyright ( 92020 N. P. Vignesh et al. This is an open access article distributed under the Creative Commons Attribution License, which permits unrestricted use, distribution, and reproduction in any medium, provided the original work is properly cited.

For this research, the red soil sample was drawn, and a steady percentage of the geopolymer was used along with distinct proportions of stabilizers such as fly ash, groundnut shell ash, bagasse ash, and GGBFS. Geopolymer was used in the manufacture of stabilized mud blocks as a binding agent. The geopolymer solution's effects on mud block strength have been researched. The effects of industrial by-products and waste such as fly ash, groundnut shell ash, bagasse ash, and GGBFS were also explored with the geopolymer to stabilize the mud blocks.

\section{Introduction}

Industry's fast growth leads to pollution generation, and issues occur when undesirable pollutants are released into the atmosphere. Much study has been carried out to minimize the production of pollutants using waste products in a variety of civil engineering applications and trails [1-6]. Soft and weak soils are often stabilized with ordinary Portland cement (OPC) and lime in civil engineering building [7]. However, the cement production method discharges $\mathrm{CO}_{2}$ into the atmosphere, which is almost $5 \%$ of the total $\mathrm{CO}_{2}$ released into the atmosphere [8]. Because of this environmental issue, industry and local authorities need to discover fresh alternatives to replace present cementitious additives with less $\mathrm{CO}_{2}$ release [9]. To solve this issue, Komnitsas and Zaharaki introduced geopolymers that could be an alternative substitute for OPC due to low-cost manufacturing and environmental friendliness. Geopolymer manufacturing needs $60 \%$ less energy, with almost $80 \%$ less $\mathrm{CO}_{2}$ compared to OPC $[10,11]$. Geopolymerization is a geosynthesis response of an alkali-activated structure from natural aluminosilicate sources. Materials rich in Si (fly ash, rice husk, and slag) and Al-rich materials (kaolinite and bentonite) were the primary requirement for geopolymerization process [11]. Moreover, due to the low temperatures engaged in processing the natural alumina-silicate with appropriate geopolymeric raw materials, this green material consumes less energy. In addition, geopolymers can be synthesized from distinct kinds of low-cost alumina-silicate products or even industrial waste such as fly ash, red mud, metakaolin, furnace slag, and rice husk ash [12-16].

\section{Materials Used}

2.1. Red Soil. Red soil was used for the preparation of mud blocks which was collected at a depth of 2 meters from Aathoor block, located in Dindigul. This red soil is rich in iron content, and the presence of iron oxides in soil enhances the properties of soil such as stability, reduction of permeability, swelling, and porosity. Hence, the presence of iron in soil is a crucial factor for enhancing the strength in the mud block [17].

2.2. Fly Ash. Fly ash is one of the residues generated in combustion and comprises the fine particles that rise with the flue gases. This finely divided ash is grey in colour, which has a specific gravity of 2.2 .

2.3. Groundnut Shell Ash. Groundnut shell is an agricultural waste obtained from the milling of the groundnut by incinerating the groundnut shell under a controlled manner; 
the groundnut shell ash was created. The ash from this groundnut shell had been categorized as a pozzolanic material based on its chemical properties. It is having a specific gravity of 2.37 .

2.4. Bagasse Ash. Bagasse is the fibrous matter that remains after sugarcane or sorghum stalks are crushed to extract their juice. It is used as a biofuel and in the manufacture of pulp and building materials. The bagasse ash has a specific gravity of 2.1.

2.5. GGBFS. GGBFS is ground granulated blast furnace slag which is produced as a by-product during the manufacture of iron in a blast furnace. Generally, it results from the fusion of limestone flux with ash from coke. The iron blast furnace slag contains primarily of silicates and alumina-silicates of lime and other bases. The GGBFS used for this study had the specific gravity of 2.85 .

2.6. Geopolymer. Geopolymer is a type of amorphous aluminosilicate cementitious material. It can be synthesized by the polycondensation reaction of the geo polymeric precursor and alkali poly-silicates known as a geopolymerization process. It involves the alkali activation to establish the bondage. The sodium hydroxide was used as an alkali activator with sodium silicate. The molarity level of geopolymer solution was maintained as 8 in this research.

\section{Mix Proportions}

The stabilized mud blocks were manufactured with the help of the red soil, geopolymer, and admixtures, and they have been mixed in certain proportions to get the stabilized mud blocks. In Table 1, the mix proportions adopted for this study are clearly shown. Raw soil does not contain any admixtures, binder, and stabilizers. The red soil and geopolymer combination was mixed with the admixtures such as fly ash, bagasse ash, groundnut ash, and GGBFS as mentioned in Table 1. In all mixes (except raw soil), geopolymer solution was added as $13.25 \%$ by weight of the red soil which had been decided based on the literature studies.

Along with the red soil and geopolymer solution, the admixture was also added up to $25 \%$ by the weight of the red soil with the increment of $5 \%$. The four wastes (industrial and agricultural) were added to the combination of red soil and geopolymer. From which, 20 different combinations of mixtures have been developed. The combinations were named as shown in Table 1 . For example, $\mathrm{GPF}_{5}$ means the mix which contains $5 \%$ of fly ash, $13.25 \%$ geopolymer, and $95 \%$ of red soil. Similarly, the nomenclature was given to the remaining mix proportions which can be understood by analyzing Table 1 . The raw soil was used to manufacture the control specimen (a reference mud block) to compare with the other specimens.

\section{Experimental Studies}

The strength and durability characteristics of mud blocks were studied based on Indiand standards $[18,19]$. The role of each ingredient and its properties on these variables was investigated. Results of the experiments by varying the constituents were analyzed to understand the behaviour of stabilized mud blocks. Geopolymeric blocks, which have been cured for 24 hours, are adequate to produce higher compressive strength. It was observed that the increase in strength was quick in 24 hours of hot air curing, but the prolongation of the curing time increased the polymerization process, resulting in improved compressive strength. Hence, the hot air curing was done for 28 days, and beyond that, there were no significant changes in strength and durability of mud blocks [20].

4.1. Compressive Strength Test. Before casting mud blocks, the red cotton soil was mixed thoroughly along with stabilizers with the help of the pan mixer as per the proportions given in Table 1. Mixing of red soil and admixtures was done in two steps such as dry mixing and wet mixing. Then, finally the geopolymer solution (13.25\%) was added. The stabilized mud blocks were cast with the help of the AURAM 3000 press. The mud blocks used in this study have a dimension of $240 \times 240 \times 100 \mathrm{~mm}$. The casted blocks had been handled very carefully and were kept on a smooth and flat surface inside the hot air oven, as shown in Figure 1. The temperature maintained inside the air oven was $60^{\circ} \mathrm{C}$ for 24 hours. The blocks made with alkaline activators with GGBFS were tested after 48 hours of casting.

The testing of the mud blocks had been done in two stages, such as dry state and wet state, to determine the dry compressive strength and wet compressive strength. The dry compressive strength results had been plotted as a bar chart which is shown in Figure 2. Similarly, the wet compressive strength of the mud blocks was determined, and the bar chart was plotted as shown in Figure 3.

4.1.1. Dry Compressive Strength Test. At a specific interval of curing, the mud blocks were subjected to compressive force using a digital compression testing machine of 300 tonnes capacity.

The testing of mud blocks was carried out for $7^{\text {th }}$ day, $14^{\text {th }}$ day, $21^{\text {st }}$ day, and $28^{\text {th }}$ day cured mud blocks. The test results of the mix GPF (soil + geopolymer + fly ash) and the mix GPGn (soil + geopolymer + groundnut ash) and the test results of the mixes GPB (Soil + geopolymer + Bagasse ash) and GPG (soil + geopolymer + GGBFS) are shown in Figure 2.

From the dry compressive strength test, the following findings were derived. The addition of the geopolymer and admixtures (GGBFS, Groundnut ash, fly ash, and bagasse ash) to raw soil (red soil) increased the dry compressive strength in a considerable percentage in all cases. The result shows that there is a gradual increment of compressive strength with an increase in the percentage of stabilizers. Among all the mixes, the four mixes such as $\mathrm{GPF}_{25}$ (12.5 MPa), GPGn 25 (13.49 MPa), GPB 25 (19.20 MPa), and $\mathrm{GPG}_{25}(30.20 \mathrm{MPa})$ had a maximum compressive strength in each combination. Out of all the mix combinations, $\mathrm{GPG}_{25}$ had more compressive strength than the other mixes, 
TABLE 1: Mix proportion of stabilized geopolymer mud blocks.

\begin{tabular}{|c|c|c|c|c|c|}
\hline Mix ID & Red soil (\%) & Fly ash (\%) & Groundnut shell ash (\%) & Bagasse ash (\%) & GGBFS (\%) \\
\hline Raw soil & 100 & - & - & - & - \\
\hline $\mathrm{GPF}_{5}$ & 95 & 5 & - & - & - \\
\hline $\mathrm{GPF}_{10}$ & 90 & 10 & - & - & - \\
\hline $\mathrm{GPF}_{15}$ & 85 & 15 & - & - & - \\
\hline $\mathrm{GPF}_{20}$ & 80 & 20 & - & - & - \\
\hline $\mathrm{GPF}_{25}$ & 75 & 25 & - & - & - \\
\hline $\mathrm{GPGn}_{5}$ & 95 & - & 5 & - & - \\
\hline $\mathrm{GPGn}_{10}$ & 90 & - & 10 & - & - \\
\hline $\mathrm{GPGn}_{15}$ & 85 & - & 15 & - & - \\
\hline $\mathrm{GPGn}_{20}$ & 80 & - & 20 & - & - \\
\hline $\mathrm{GPGn}_{25}$ & 75 & - & 25 & - & - \\
\hline $\mathrm{GPB}_{5}$ & 95 & - & & 5 & - \\
\hline $\mathrm{GPB}_{10}$ & 90 & - & & 10 & - \\
\hline $\mathrm{GPB}_{15}$ & 85 & - & & 15 & - \\
\hline $\mathrm{GPB}_{20}$ & 80 & - & & 20 & - \\
\hline $\mathrm{GPB}_{25}$ & 75 & - & & 25 & - \\
\hline $\mathrm{GPG}_{5}$ & 95 & - & & & 5 \\
\hline $\mathrm{GPG}_{10}$ & 90 & - & & & 10 \\
\hline $\mathrm{GPG}_{15}$ & 85 & - & & & 15 \\
\hline $\mathrm{GPG}_{20}$ & 80 & - & & & 20 \\
\hline $\mathrm{GPG}_{25}$ & 75 & - & & & 25 \\
\hline
\end{tabular}

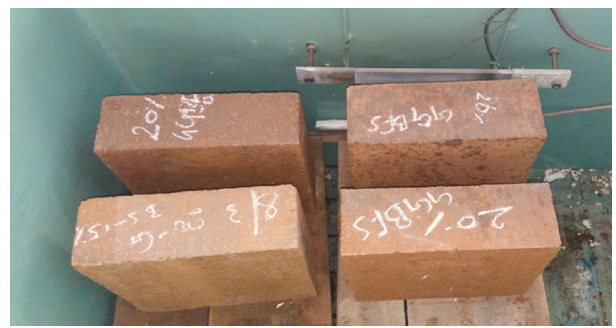

FIgURE 1: Curing of stabilized geopolymer mud blocks.

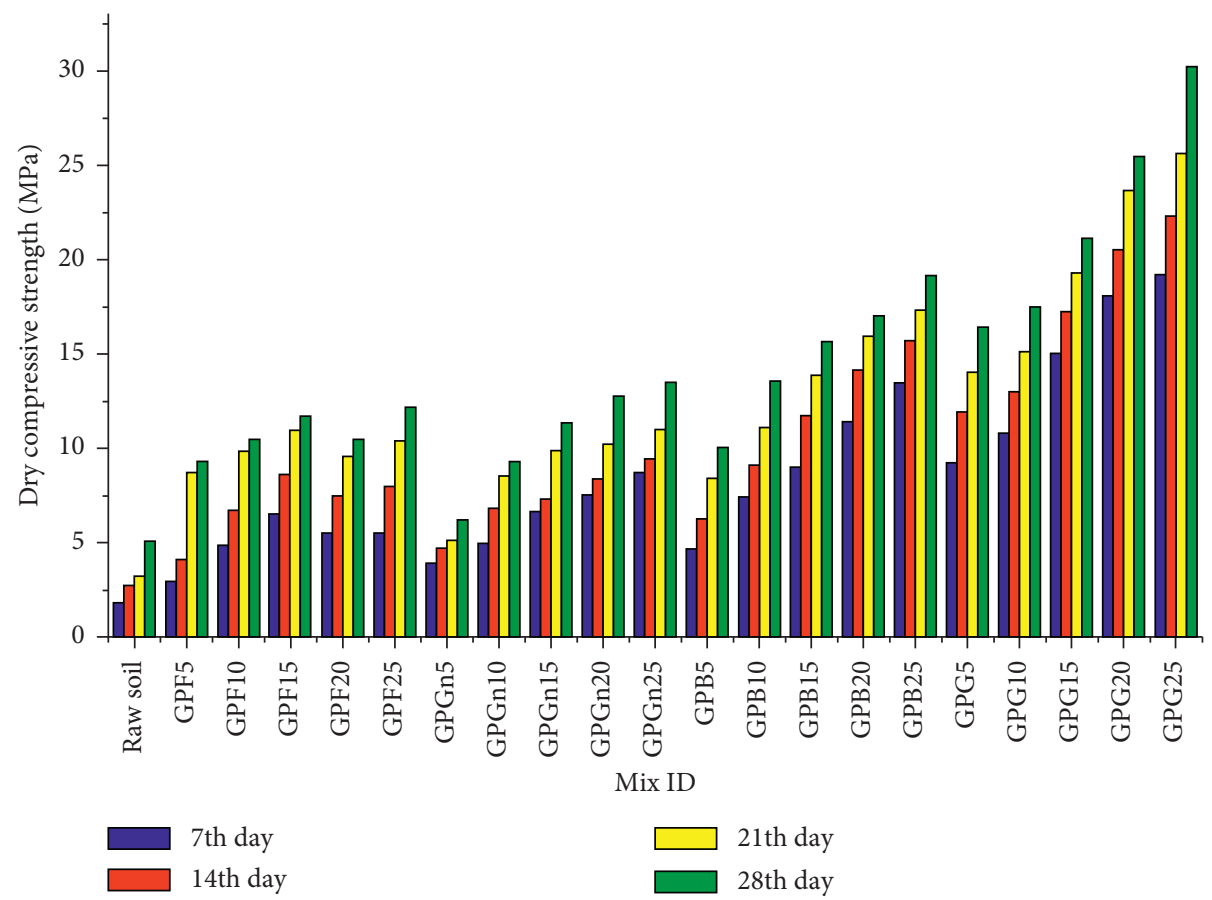

FIGURE 2: Dry compressive strength for stabilized geopolymer mud blocks. 


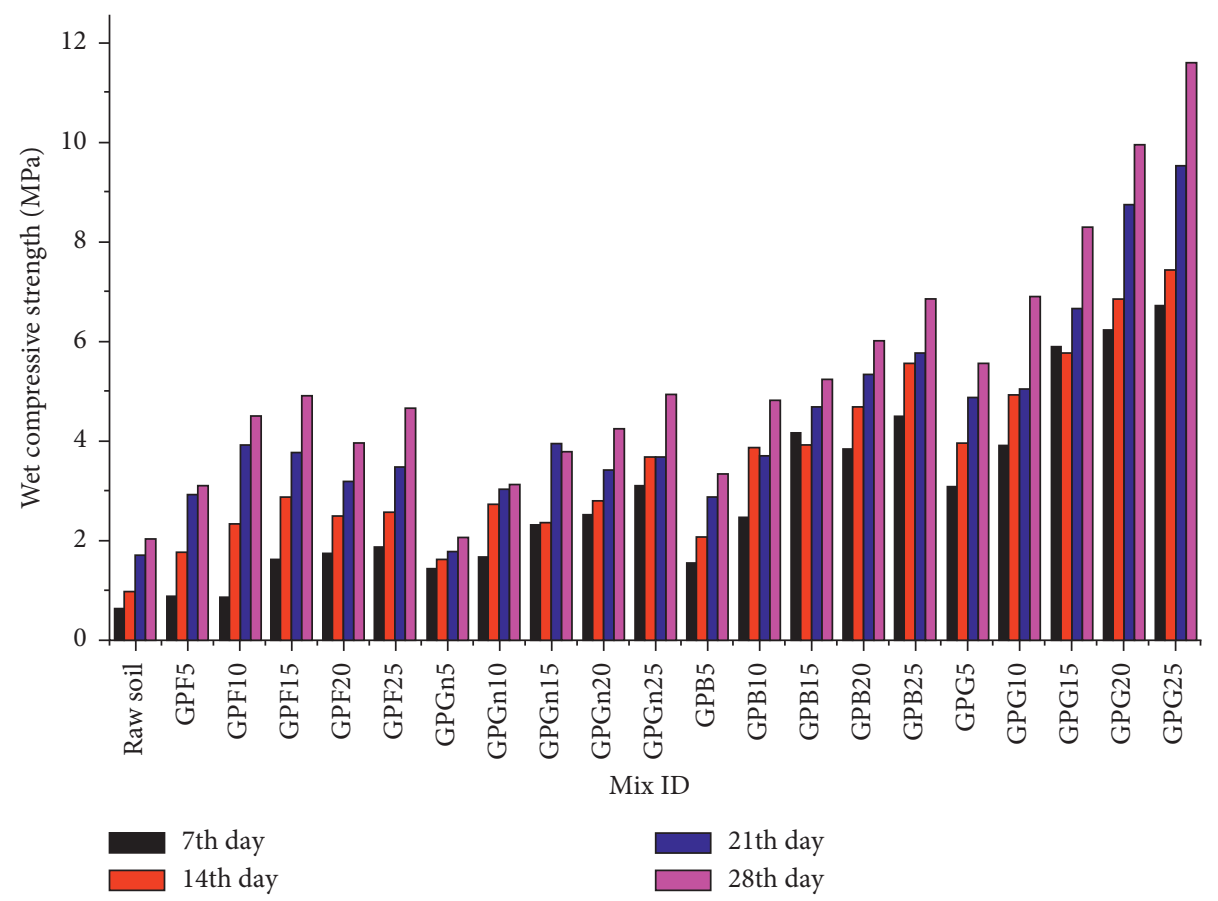

Figure 3: Wet compressive strength for stabilized geopolymer mud blocks.

and it was 4.9 times more than that of the raw soil mud block. $\mathrm{GPF}_{25}$ had 1.4 times more compressive strength than the raw soil mud block.

Similarly, the compressive strength of $\mathrm{GPGn}_{25}$ mix was 1.64 times more than the compressive strength of raw soil mud block. The $\mathrm{GPB}_{25}$ mix had 2.75 times more compressive strength than the raw soil mud block. Among all the mixes, the compressive strength of mud blocks made by raw soil had the least value. Thus, the addition of the stabilizers and geopolymer increased the dry compressive strength of the mud blocks and stability of the mud blocks.

4.1.2. Wet Compressive Strength. The wet compressive strength test was conducted after 48 hours immersion of mud blocks in water. This test was carried out in a digital compression testing machine. The test results had been plotted as a bar chart and are shown in Figure 3 [21].

Based on the above-plotted charts, the following findings were observed from the plotted bar charts. The result shows that there was a gradual increment of compressive strength with an increase in the percentage of the stabilizer. Among all the mixes, the four mixes such as $\mathrm{GPF}_{25}(4 \mathrm{MPa}), \mathrm{GPGn}_{25}(4.96 \mathrm{MPa}), \mathrm{GPB}_{25}(6.84 \mathrm{MPa})$, and $\mathrm{GPG}_{25}(11.60 \mathrm{MPa})$ had a maximum compressive strength in each combination. Out of all the mix combinations, the $\mathrm{GPG}_{25}$ mix had more compressive strength than the other mixes, and it was 4.72 times more than the raw soil mud block. The percentage increases of compressive strength for the mixes GPF25, GPGn25, and GPB25 were $130 \%, 144 \%$, and $237 \%$, respectively. It was noted that the strength achieved by the mixes was greater than the control specimen. The mud blocks produced from the raw mix had less compressive strength than that of the mud blocks manufactured from all the mixes. Thus, the incorporation of the geopolymer and other stabilizers increased the wet compressive strength of the mud blocks. Thus, the stabilization of the mud blocks was possible to achieve by using these admixtures.

4.2. Flexural Strength. Flexural strength is also known as modulus of rupture and is the limit at which a material can withstand flexural stress. This test was conducted based on IS 4332 (Part VI): 1972 after 28 days of curing. When an object is subjected to flexural stress, it undergoes both tension and compression because of the bending moment. The flexural strength of the material will depend on either its tensile strength or compressive strength, whichever is lesser. The above standard covers the procedure for determining the flexural strength of soil by the use of a simple beam with third point loading. The flexural strength results for the mud blocks made up of GPF, GPGn, GPB, and GPG are shown in Figure 4.

Concerning the flexural strength test results, the following findings had been found. Generally, the compressive strength is directly proportional to the flexural strength. Similar to compressive strength, the flexural strength was found to be greater than the control specimen. The flexural strength for the mix $\mathrm{GPF}_{25}(2.12 \mathrm{MPa})$ had $69.6 \%$ more flexural strength than the flexural strength of the raw soil mud block. The mix $\mathrm{GPGn}_{25}$ had $142 \%$ more flexural strength than the raw soil mix. The modulus of rupture from the mix $\mathrm{GPB}_{25}$ was $225 \%$ more than the modulus of rupture from the raw soil. Similarly, the mix $\mathrm{GPG}_{25}$ had $208.8 \%$ more flexural strength than the raw soil. Thus, the mud block 


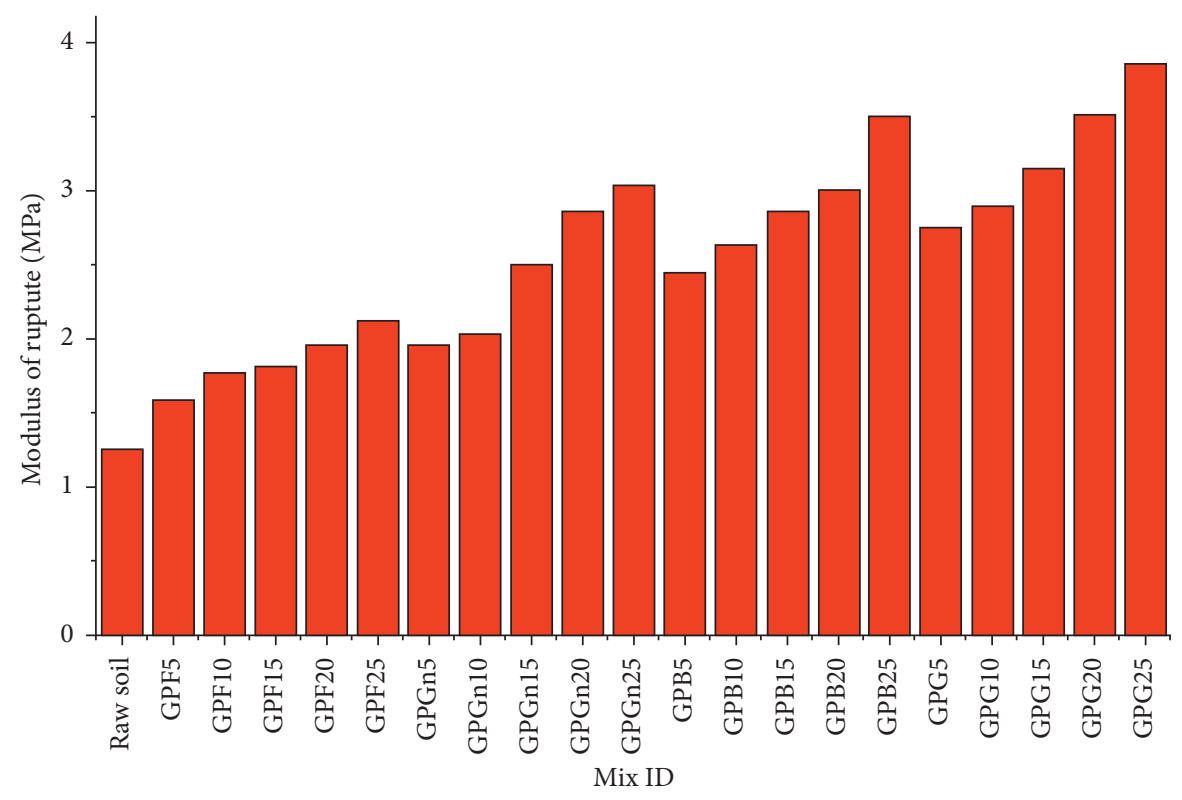

FIGURE 4: Flexural strength for stabilized geopolymer mud blocks.

manufactured from the mix $\mathrm{GPG}_{25}$ had the highest flexural strength than the mud blocks from all mixes.

From Figure 4, it was found that the flexural strength increased with the increase of admixture. The presence of admixture and geopolymer in red soil reacted to the soil and made it as a stabilized one. The mud blocks from the raw soil had least flexural strength than the all stabilized mud blocks.

4.3. Prism Test. It was conducted by arranging the mud blocks one over another which consists of three numbers and also five numbers. After 28 days of curing, this experiment was carried out to evaluate the block efficiency and prism strength for both 3-block pattern and 5-block pattern. The $h / t$ ratio of $300 \mathrm{~mm}$ and $500 \mathrm{~mm}$ length specimens was 3.0 and 5.0, respectively. The test results from the prism test for all the combination are shown in Figure 5. For every soil stabilizer combination, the block efficiency of 3-block and 5block prism was found individually, and the discussion of the results is discussed in the next paragraph.

From the plotted charts, the following discussions were made. The efficiency of the stabilizer-added mud blocks was decreasing gradually and reached the lesser value (approximately equal to 1) which is lesser than the efficiency of the raw soil mud block. Thus, the unit block strength and masonry block strength attained almost equal strength in the $25 \%$ replacement by the stabilizer, in all four cases. From Figure 5, it was observed that the efficiency of the 3 blocks and 5 blocks for the mix $\mathrm{GPF}_{25}$ had $54.64 \%$ and $41.66 \%$ less than that of the raw soil mud block. Similarly, the efficiency of the 3 blocks and 5 blocks for the mix GPGn $_{25}$ had $48.66 \%$ and $40.19 \%$ than that of the raw soil mud block. The mix $\mathrm{GPB}_{25}$ had $62.51 \%$ and $48.84 \%$ less value of 3 blocks and 5 block efficiency than that of raw soil mud block. The efficiency of the raw soil for 3 blocks and 5 blocks was $63.76 \%$ and $49.17 \%$ more than that of the mix $G_{P G}$.
4.4. Water Absorption. The water absorption test was carried out as per IS: 3495 . This experiment was performed to determine the water absorption and rate of moisture absorption of the bricks with the time of soaking in water. This test was done after the geopolymer mud blocks were cured for 28 days. The blocks were dried in an oven at $60^{\circ} \mathrm{C}$ until they attained constant weight. The weights of dried blocks were recorded. Then, the dried blocks were immersed in freshwater for $24 \mathrm{hrs}$. After soaking in the water, they were removed and wiped with a damp cloth.

The final weight of the brick was measured. From the measured values, the water absorption of the mud blocks was found and is shown in Figure 6.

From the results obtained, it has been found that all the blocks have satisfactory water absorption value. The water absorption capacity of the mud blocks had been reduced well due to the addition of the stabilizers. The mix $\mathrm{GPF}_{25}$ had $28.96 \%$ less water absorption capacity than the raw soil. The mix $\mathrm{GPG}_{25}$ had $67.58 \%$ less value of water absorption than the raw soil. The water absorption of the mix $\mathrm{GPB}_{25}$ possessed $106.08 \%$ less than the water absorption of the raw soil. Similarly, the water absorption of the mix GPG25 was 2.51 times higher than the control specimen. Among all the mixes, the mix $\mathrm{GPG}_{25}$ (3.47\%) had the least value of water absorption. When compared with all the mixes, the raw soil mud block $(12.20 \%)$ had more value of water absorption. Thus, the reduction of the water absorption capacity of the mud blocks depended upon the stabilizers added and its percentage of partial replacement. The stabilizers, viz., GGBFS, bagasse ash, groundnut shell ash, and fly ash are treated as important stabilizers since they have water-resisting characteristics.

4.5. Spray Erosion. The spray erosion test was conducted to determine the rate of erosion as per IS 1725-1982. The depth of penetration was measured for every $5,10,30$, and 60 

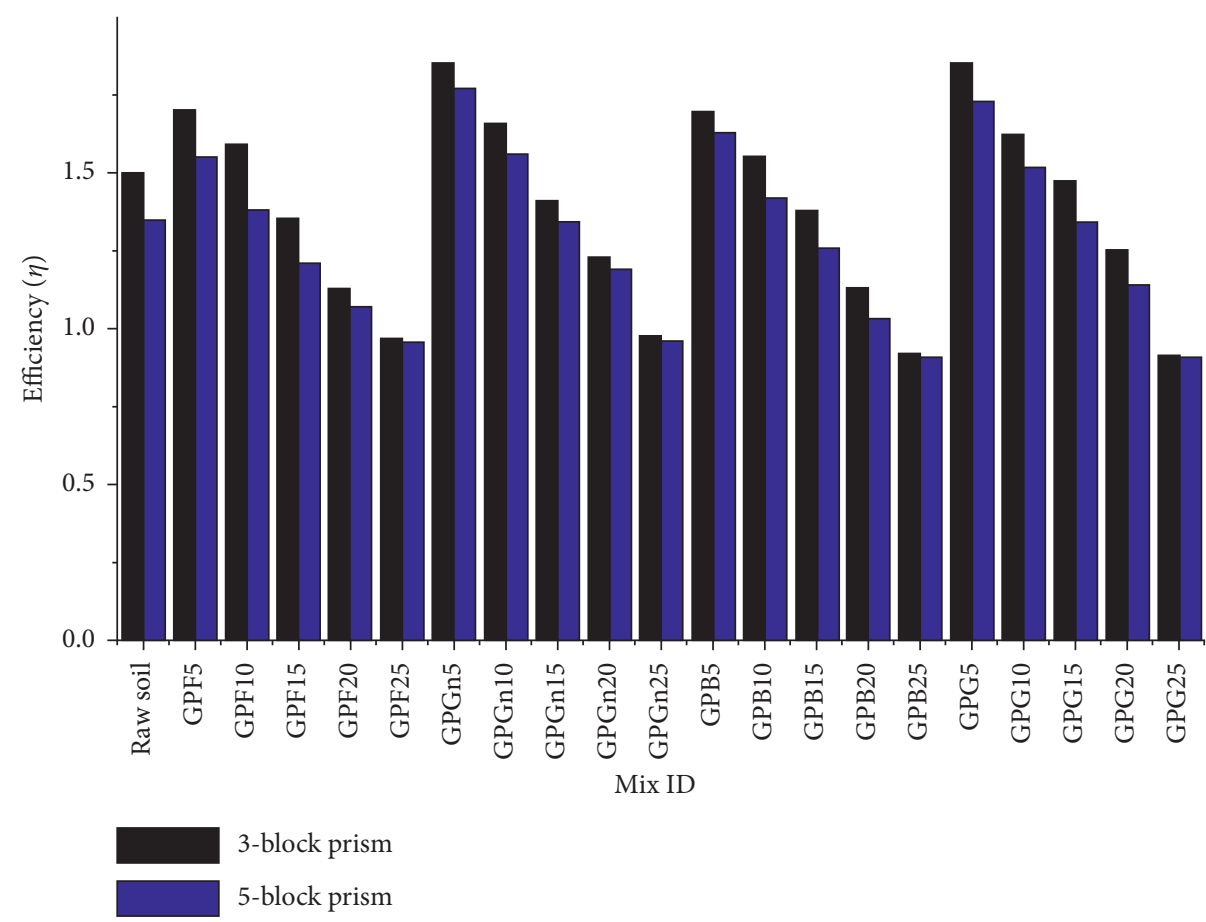

Figure 5: The efficiency of stabilized geopolymer mud blocks.

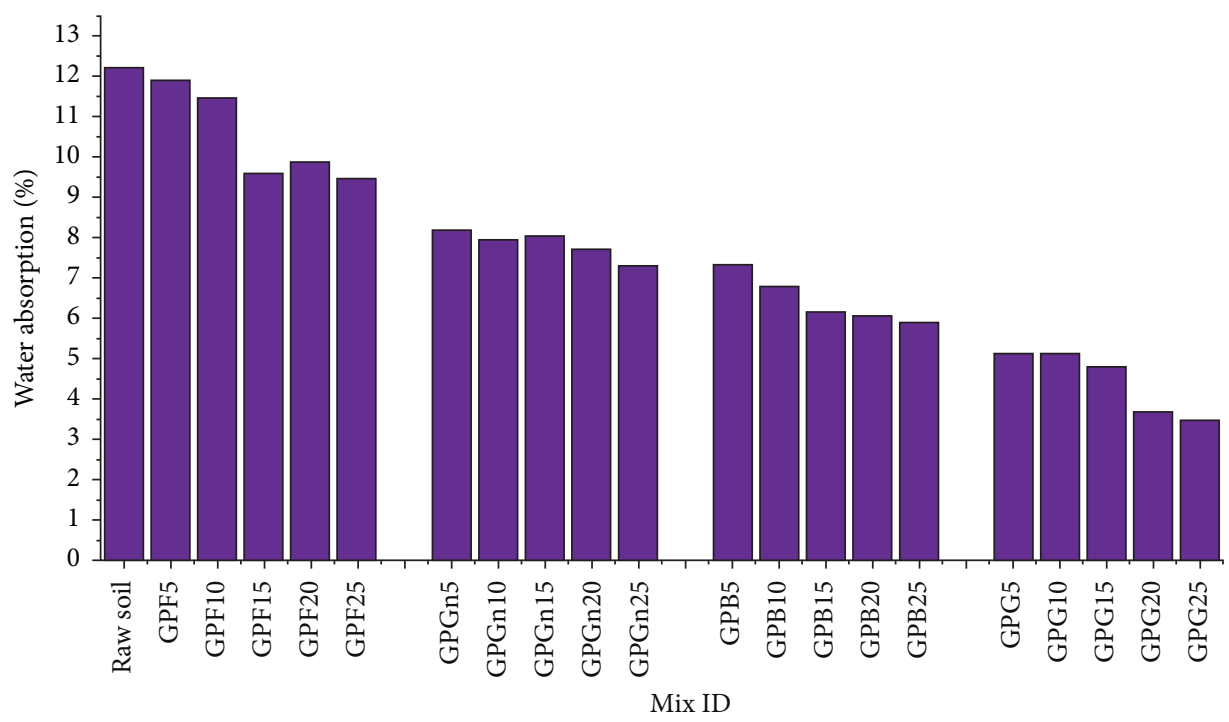

FIGURE 6: Water absorption of stabilized geopolymer mud blocks.

minutes, and the period of exposure was limited to 2 hours, and then the exposed surfaces were examined for possible pitting. The tests were carried out on at least 3 blocks after 28 days of curing. The depth of penetration should not exceed $2 \mathrm{~cm}$ for 1 hour of spray as per IS codal provision. The test results are shown in Figure 7.

From the plotted graph, the following findings were made for spray erosion test. The rate of erosion value of the stabilized mud blocks decreased with the increment of the percentage of the stabilizers. In GPF combination, the rate of erosion for the $\mathrm{GPF}_{25}$ combination was $21.25 \%$ more than that of the raw soil mud block.
But, $\mathrm{GPF}_{5}, \mathrm{GPF}_{10}, \mathrm{GPF}_{15}$, and $\mathrm{GPF}_{20}$ had more value in the rate of erosion when compared to the raw soil mud block. Similarly, in GPF, GPG and GPGn combination also had a higher rate of erosion (from $5 \%$ to $20 \%$ ) while compared to the raw soil mud block, and they were in decreasing order with their percentage increment. GPGn ${ }_{25}$ combination had $40.35 \%$ less value of spray erosion than that of the raw soil combination, and the spray erosion of the $\mathrm{GPB}_{25}$ combination had $122.22 \%$ less value of the rate of erosion than that of the raw soil mud block. $\mathrm{GPG}_{20}$ and $\mathrm{GPG}_{25}$ combinations had $220 \%$ and $371 \%$ lesser value of the rate of erosion, respectively, when compared to the rate of erosion of the raw soil mud 


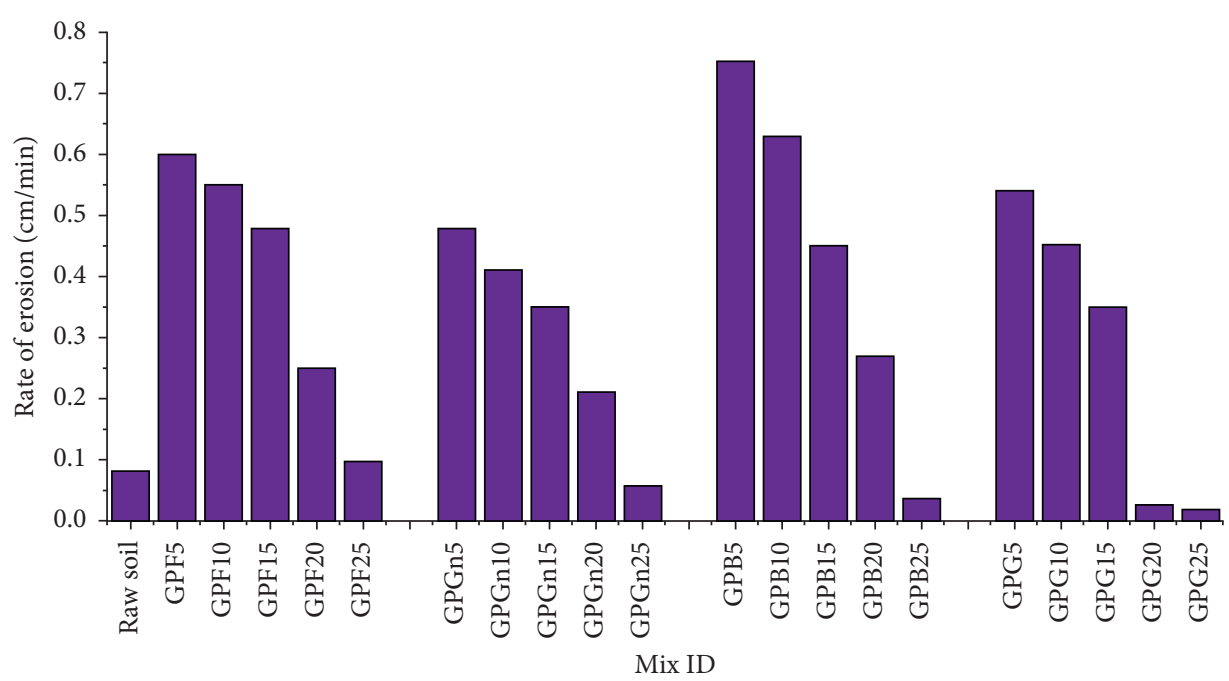

FIgURE 7: Spray erosion of stabilized geopolymer mud blocks.

block. Among all the soil stabilizer combinations, $\mathrm{GPG}_{20}$ and $\mathrm{GPG}_{25}$ had the least value of the rate of erosion. Thus, the addition of the GGBFS in the raw soil geopolymer combination increased the resistance for erosion.

4.6. SEM Analysis. From the evaluated results of the various tests such as compressive strength test, flexural strength test, water absorption test, spray erosion test, and block test, the suitable soil stabilizer combinations have been chosen, and the SEM images for such soil stabilizer combinations have been taken for the analysis. Figure 8 shows the SEM images of the best soil stabilizer combinations $\left(\mathrm{GPB}_{25}, \mathrm{GPF}_{25}, \mathrm{GPGn}_{25}\right.$, and $\mathrm{GPG}_{25}$ ). Almost all the microimages of the soil stabilizers combinations were taken in $20 \mu \mathrm{m}$. The edges of the soil stabilizer $\left(\mathrm{GPB}_{25}\right)$ particles are round in shape and have some pores in it. The dark portion in the image may represent the presence of the bagasse ash and the liner patches may be indicated the geopolymer which is present in all the microimages. The micro image of the soil stabilizer GPF 25 has sphere-like elements that signify the soil with fly ash, and the convolution indicates the presence of voids. The SEM image of $\mathrm{GPG}_{25}$ has a number of voids compared to the other SEM images. The round-shaped black particles are found in the SEM image of soil stabilizer $\mathrm{GPGn}_{25}$, and the particles present in the mix are well bound together and have less void among all the mixes.

4.7. Model for Predicting the Compressive Strength of Red Soil Mud Blocks. From the experimental study, it has been observed that the compressive strength of mud blocks without geopolymer varies with the strength of the various types of mix and the additional proportion $13.25 \%$ of the geopolymer. The proportions adopted for making of mud blocks such as red soil (75\% to $100 \%)$ and varying percentage of admixture for different mix such GPF (5\% to $25 \%$ of fly ash), GPGn (5\% to $25 \%$ of groundnut shell ash), GPB ( $5 \%$ to $25 \%$ of Bagasse ash), and GPG (5\% to $25 \%$ of GGBFS) were taken for the prediction model.
Red Soil and different ration of admixture are having a direct effect on the compressive strength of the mud blocks. After reviewing various proportions of sand, soil, and admixture reported in Table 1 and Figure 2, the parameters, i.e., compressive strength of red soil mud blocks (C), type of mix (TM), and soil (RSO), have been identified in this study. A statistical study was conducted to identify the significance of the identified parameters, and the ANOVA results are given in Table 2.

From Table 2, it can be seen that $F$-value is greater than $F$-critical value (3.86) and sig-value is less than 0.05 corresponding to all parameters. Hence, it is established that all the parameters considered have a significant influence on the compressive strength of mud blocks.

Table 3 shows the fitness of the model. The developed model could predict $91 \%$ of compressive strength of mud block using different types of mix (TM) and various proportions of red soil (RSO).

From Table 4, the parameters type of mix (0.78) and red soil $(-0.52)$ are found to have the maximum influence on the compressive strength. Statistical regression analysis was carried out using observed data from the experimental study, and the details of the data are given in Table 1 and Figure 2. The type of mix, percentage of soil, and percentage of geopolymer used for the analysis are presented in $\mathrm{Ta}$ ble 1 . Test data corresponding to the compressive strength (5.11 to $30.20 \mathrm{MPa}$ ), Type of Mix (Raw, GPF, GPGn, GPB, and GPG) and soil (100\% to $75 \%)$. However, for GPF mix (5\% to $25 \%$ of fly ash and additional $13.25 \%$ of geo polymer), GPGn mix (5\% to $25 \%$ of groundnut shell ash and additional $13.25 \%$ of geopolymer). GPB (5\% to $25 \%$ of Bagasse and additional $13.25 \%$ of Geopolymer) and GPG ( $5 \%$ to $25 \%$ of GGBFS and additional $13.25 \%$ of geopolymer) were used in the regression analysis. The prediction equation (1) for compressive strength using linear regression models is

$$
C=3.83 * T M-0.41 * R S 0-0.46 * G+41.88 .
$$




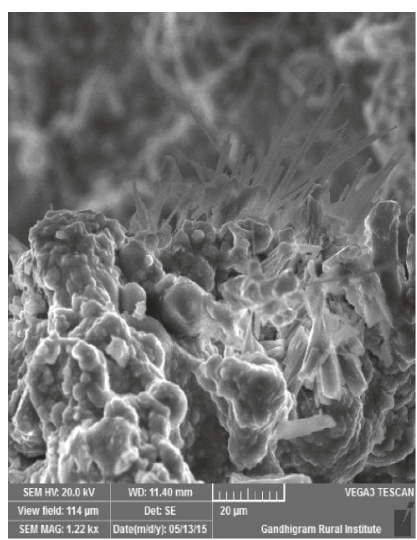

(a)

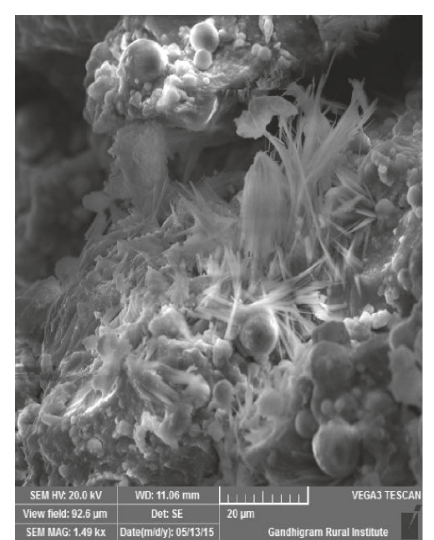

(b)

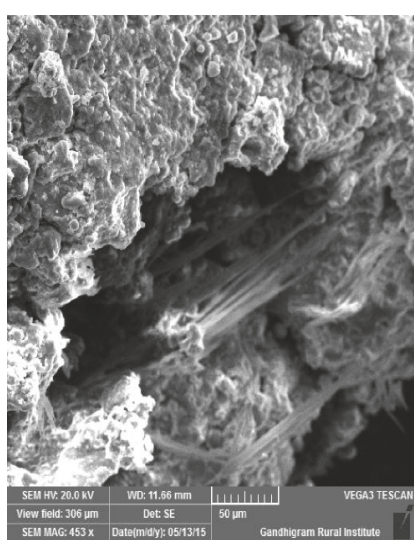

(c)

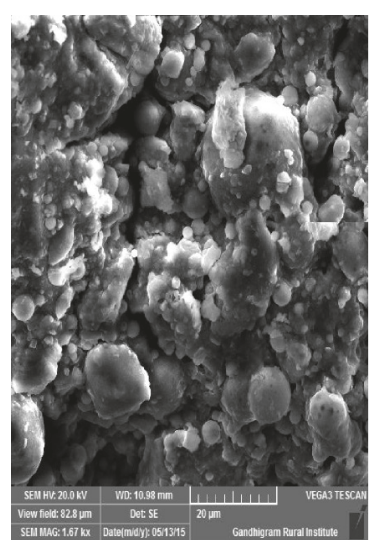

(d)

FIgURE 8: SEM images of (a) $\mathrm{GPB}_{25}$, (b) $\mathrm{GPF}_{25}$, (c) $\mathrm{GPG}_{25}$, and (d) $\mathrm{GPGn}_{25}$.

TABLE 2: Significance relation between sand, soil, and admixture.

\begin{tabular}{llcccc}
\hline Model & & Sum of squares & df & Mean square & $F$ \\
\hline \multirow{2}{*}{1} & Regression & 618.75 & 3 & 206.25 & 28.53 \\
& Residual & 122.90 & 17 & 7.23 & $0.00^{\mathrm{b}}$ \\
& Total & 741.65 & 20 & & \\
\hline
\end{tabular}

${ }^{\mathrm{a}}$ Dependent variable: compressive strength. ${ }^{\mathrm{b}}$ Predictors: (constant), GEO polymer, red cotton soil, and type of mix.

TABLe 3: Fitness of model for red soil.

\begin{tabular}{lcccc}
\hline Model & $R$ & $R$ square & Adjusted $R$ square & Std. error of the estimate \\
\hline 1 & $0.91^{\mathrm{a}}$ & 0.83 & 0.80 & 2.69 \\
\hline
\end{tabular}

${ }^{a}$ Predictors: (constant), GEO polymer, red cotton soil, type of mix.

TABLE 4: Coefficients of mud block using red soil with admixture.

\begin{tabular}{|c|c|c|c|c|c|c|}
\hline \multirow[t]{2}{*}{ Model } & & \multicolumn{2}{|c|}{$\begin{array}{l}\text { Unstandardized } \\
\text { coefficients }\end{array}$} & \multirow{2}{*}{$\begin{array}{c}\text { Standardized coefficients } \\
\text { Beta }\end{array}$} & \multirow[t]{2}{*}{$t$} & \multirow[t]{2}{*}{ Sig. } \\
\hline & & $B$ & Std. error & & & \\
\hline \multirow{4}{*}{1} & Constant & 41.88 & 8.93 & & 4.69 & 0.00 \\
\hline & Red cotton soil (RSO) & -0.41 & 0.09 & -0.52 & -4.78 & 0.00 \\
\hline & Type of mix (TM) & 3.83 & 0.54 & 0.78 & 7.12 & 0.00 \\
\hline & GEO polymer $(\mathrm{G})$ & -0.46 & 0.25 & -0.21 & -1.83 & 0.08 \\
\hline
\end{tabular}

Dependent variable: compressive strength.

\section{Conclusion}

From the test results, the following conclusions were found. Incorporating the stabilizers increased their compressive strength, flexural strength, spray erosion resistance, and block strength and decreased the water absorption capacity. The geopolymer (13.25\%) was added to soil to prepare all mixes. Four different stabilizers (fly ash, groundnut ash, bagasse ash, and GGBFS) were added to produce the stabilized mud blocks. Among all the mixes, the mix which contained GGBFS had good strength as well as durability properties than the other stabilizers. The 45 to 50 percentage partial replacement of GGBFS to red soil with the addition of $13.25 \%$ geopolymer combination shows better results among the other mix proportion. Finally, the linear regression model was proposed to find the compressive strength of red soil mud block using a different proportion of red soil with different percentages of admixture along with geopolymer.

\section{Data Availability}

The data used to support the findings of the study are included within the article.

\section{Conflicts of Interest}

The authors declare that they have no conflicts of interest. 


\section{References}

[1] R. Taha, A. Al-Harthy, K. Al-Shamsi, and M. Al-Zubeidi, "Cement stabilization of reclaimed asphalt pavement aggregate for road bases and subbases," Journal of Materials in Civil Engineering, vol. 14, no. 3, pp. 239-245, 2002.

[2] W.-L. Huang, D.-H. Lin, N.-B. Chang, and K.-S. Lin, "Recycling of construction and demolition waste via a mechanical sorting process," Resources, Conservation and Recycling, vol. 37, no. 1, pp. 23-37, 2002.

[3] H. Akbulut and C. Gürer, "Use of aggregates produced from marble quarry waste in asphalt pavements," Building and Environment, vol. 42, no. 5, pp. 1921-1930, 2007.

[4] E. Mutaz, M. A. Shamrani, A. J. Puppala, and M. A. Dafalla, "Evaluation of chemical stabilization of a highly expansive clayey soil," Transportation Research Record: Journal of the Transportation Research Board, vol. 2204, no. 1, pp. 148-157, 2011.

[5] A. Pedarla, S. Chittoori, and A. J. Puppala, "Influence of mineralogy and plasticity index on the stabilization effectiveness of expansive clays," Transportation Research Record: Journal of the Transportation Research Board, vol. 2212, no. 1, pp. 91-99, 2011.

[6] A. Arulrajah, M. M. Disfani, S. Horpibulsuk, C. Suksiripattanapong, and N. Prongmanee, "Physical properties and shear strength responses of recycled construction and demolition materials in unbound pavement base/subbase applications," Construction and Building Materials, vol. 58, pp. 245-257, 2014.

[7] A. Arulrajah, M. M. Y. Ali, M. M. Disfani, J. Piratheepan, and M. W. Bo, "Geotechnical performance of recycled glass-waste rock blends in footpath bases," Journal of Materials in Civil Engineering, vol. 25, no. 5, pp. 653-661, 2013.

[8] S. Horpibulsuk, C. Phetchuay, A. Chinkulkijniwat, and A. Cholaphatsorn, "Strength development in silty clay stabilized with calcium carbide residue and fly ash," Soils and Foundations, vol. 53, no. 4, pp. 477-486, 2013.

[9] M. Fareed Ahmed, M. Fadhil Nuruddin, and N. Shafiq, "Compressive strength and workability characteristics of low calcium fly ash based self-compacting geopolymer concrete," Engineering, and Technology, vol. 74, pp. 8-14, 2011.

[10] K. Komnitsas and D. Zaharaki, "Geopolymerisation: a review and prospects for the minerals industry," Minerals Engineering, vol. 20, no. 14, pp. 1261-1277, 2007.

[11] D. Khale and R. Chaudhary, "Mechanism of geopolymerization and factors influencing its development: a review," Journal of Materials Science, vol. 42, no. 3, pp. 729-746, 2007.

[12] G. Zhang, J. He, and R. P. Gambrell, "Synthesis, characterization, and mechanical properties of red mud-based geopolymers," Transportation Research Record: Journal of the Transportation Research Board, vol. 2167, no. 1, pp. 1-9, 2010.

[13] I. Giannopoulou, D. Dimas, I. Maragkos, and D. Panias, "Utilization of solid metallurgical by-products for the development of inorganic polymeric construction materials," Global Nest International Journal, vol. 11, no. 2, pp. 127-136, 2009.

[14] V. A. Mymrin and A. J. Vázquez-Vaamonde, "Red mud of aluminium production waste as a basic component of new construction materials," Waste Management \& Research, vol. 19, no. 5, pp. 465-469, 2001.

[15] Z. Pan, D. Li, J. Yu, and N. Yang, "Properties and microstructure of the hardened alkali-activated red mud-slag cementitious material," Cement and Concrete Research, vol. 33, no. 9, pp. 1437-1441, 2003.

[16] S. Detphan and P. Chindaprasirt, "Preparation of fly ash and rice husk ash geopolymer," International Journal of Minerals, Metallurgy and Materials, vol. 16, no. 6, pp. 720-726, 2009.

[17] S. Goldberg, "Interaction of aluminum and iron oxides and clay minerals and their effect on soil physical properties: a review," Communications in Soil Science and Plant Analysis, vol. 20, no. 11-12, pp. 1181-1207, 1989.

[18] Bureau of Indian Standards, IS 1725 Specification for Soil Based Blocks Used in General Building Construction, Bureau of Indian Standards, New Delhi, India, 1982.

[19] Bureau of Indian Standards, IS 3495 (Parts 1 to 4): Methods of Tests of Burnt Clay Building Bricks, Bureau of Indian Standards, New Delhi, India, 1992.

[20] D. Hardjito and B. V. Rangan, Development and Properties of Low Calcium Fly Ash Based Geopolymer Concrete, Research Report GC-1, Curtin University of Technology, Perth, Australia, 2005.

[21] K. S. Jagadish, Building with Stabilized Mud, I. K. International Publishing House Pvt. Ltd., New Delhi, India, 2007. 


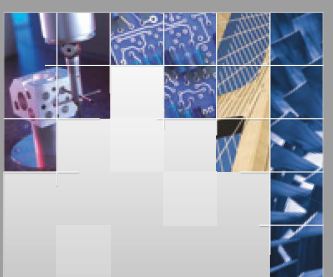

\section{Enfincering}
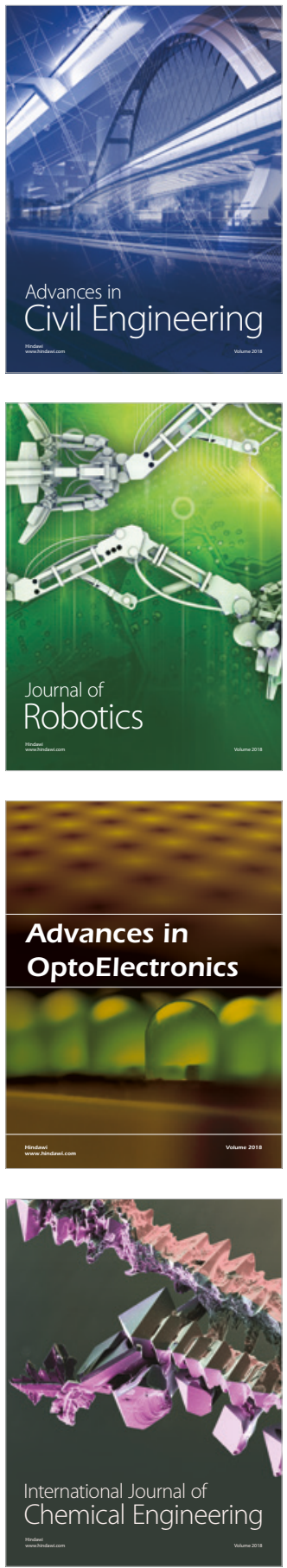

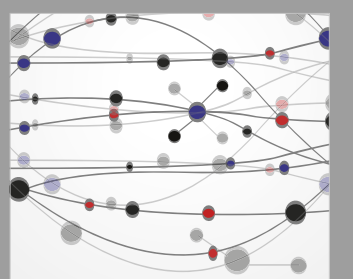

\section{Rotating \\ Machinery}

The Scientific World Journal

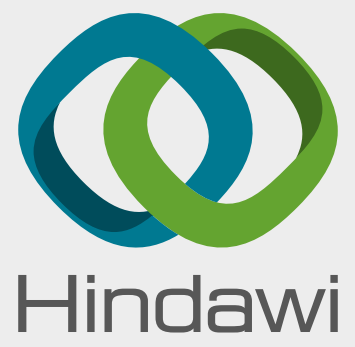

Submit your manuscripts at

www.hindawi.com
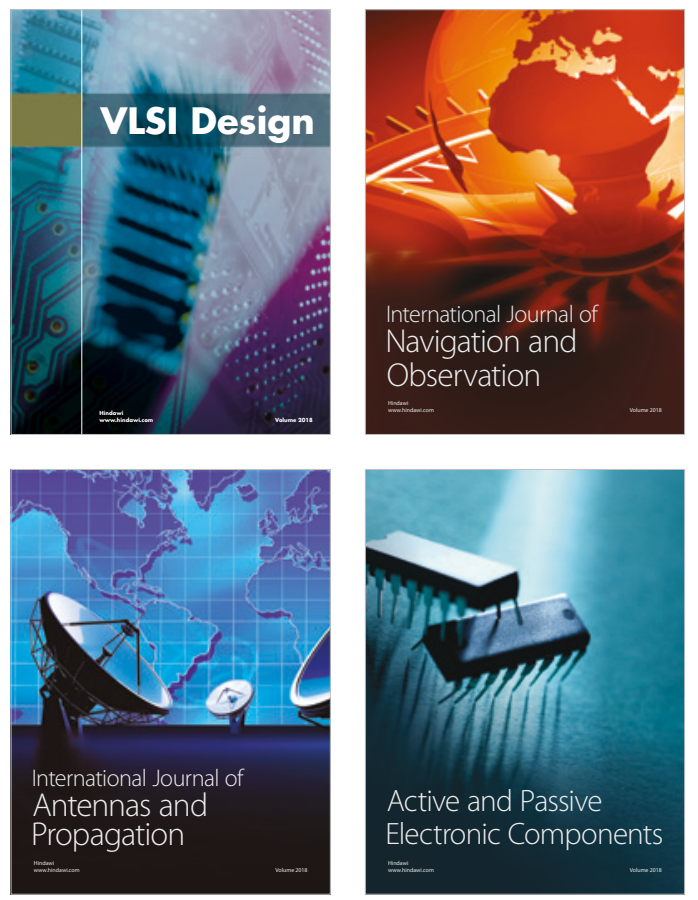
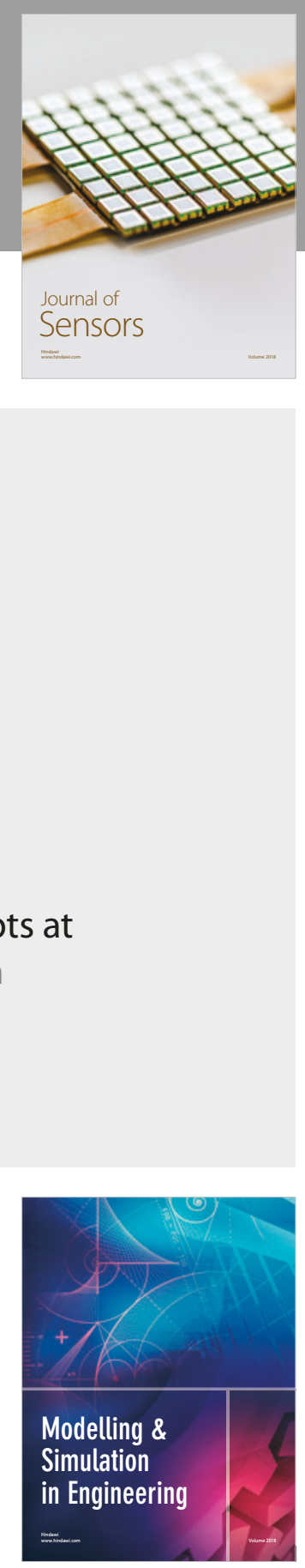

\section{Advances \\ Multimedia}
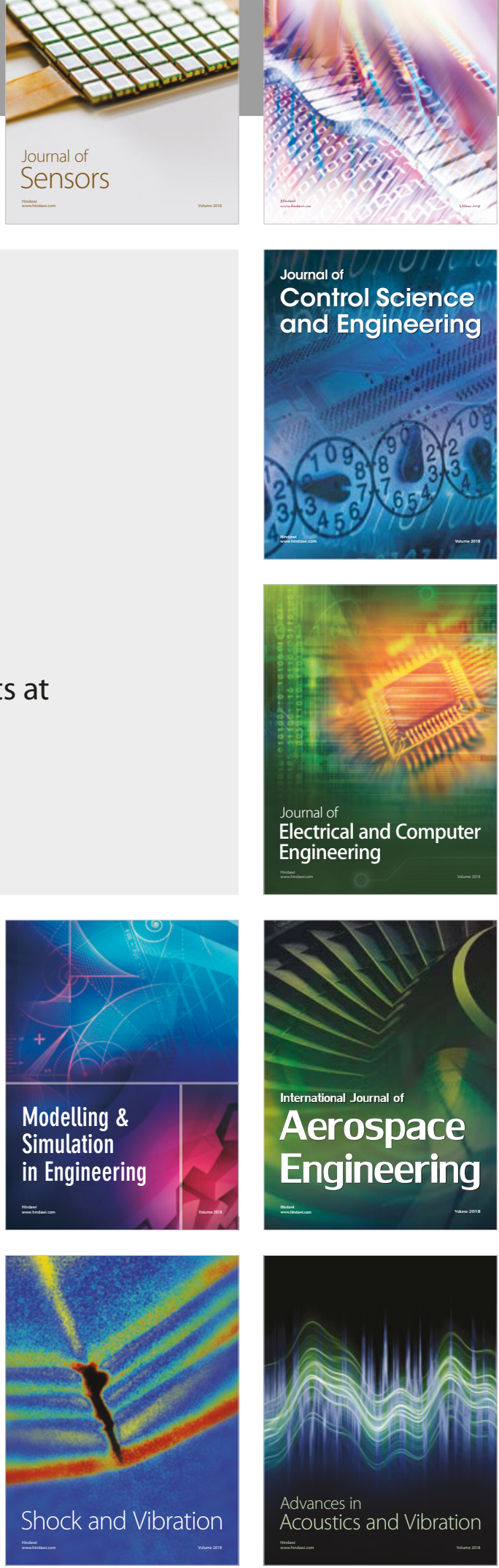